\title{
On the specific graphic, orthographic and morphological features of the usus of the monastic scriptoria of Nuremberg in the $15^{\text {th }}$ century
}

\author{
A. E. Gavriusheva ${ }^{1}$
}

${ }^{1}$ P. G. Demidov Yaroslavl State University, 14 Sovetskaya str., Yaroslavl 150003, Russian Federation

DOI: 10.18255/2412-6519-2021-1-88-95

Research Article

Full text in Russian

The article examines the graphic, spelling and morphological features characteristic for medieval texts created in Nuremberg. The study involves spiritual literature created in various Nuremberg scriptoria. Each investigated text is considered as an integral and independent graphic and spelling system, consisting of interrelated elements. Following features presented in the studied manuscripts are revealed in the course of the analysis of the texts: the Middle and Early New High German features, features characteristic of the Southeastern, East Frankish and Nuremberg dialects, as well as the spelling features. The reasons for the differences between the graphic and spelling systems of the studied texts from the phonetic system of Early New High German and intertextual differences are subject to interpretation. The analysis of the scriptoria peculiarities makes it possible to determine the place of graphic and orthographic systems in the context of Early New High German linguistic dynamics, as well as the degree of influence of various dialects on them. When considering the graphic and orthographic features of the studied texts, the specificity of the written fixation of Early New High German is taken into account as well as the fact that the urban written language and the urban dialect are different sources of influence on the formation of the written tradition of each scriptorium. This study allows to conclude about the degree of independence of the graphic and spelling systems of manuscripts and about the usability of the norms of the written language of the period under study.

Keywords: graphic features; spelling features; morphological features; monastic usus; written language; Nuremberg dialect; Early New High German

INFORMATION ABOUT THE AUTHORS

\begin{tabular}{l|l} 
Gavriusheva, Alexandra E. & $\begin{array}{l}\text { E-mail: alexandra-gavr@mail.ru } \\
\text { Senior lecturer }\end{array}$
\end{tabular}

For citation: Gavriusheva A. E. On the specific graphic, orthographic and morphological features of the usus of the monastic scriptoria of Nuremberg in the 15th century // Social'nye i gumanitarnye znanija. 2021. Vol. 7, No 1. P. 88-95. (in Russ.) 


\title{
О специфических графико-орфографических и морфологических чертах узуса монастырских скрипториев Нюрнберга XV века
}

\author{
А. Е. Гаврюшева ${ }^{1}$
}

1Ярославский государственный университет им. П. Г. Демидова, ул. Советская, 14, Ярославль, 150003, Российская Федерация

DOI: $10.18255 / 2412-6519-2021-1-88-95$

УДК 811.11-112.2

Научная статья

Полный текст на русском языке

В статье рассматриваются графико-орфографические и морфологические особенности, характерные для средневековых текстов, созданных в Нюрнберге. К исследованию привлекается духовная литература, созданная в скрипториях конвентов св. Клары и св. Екатерины. Каждый исследуемый текст рассматривается как целостная и самостоятельная графико-орфографическая система, состоящая из взаимосвязанных элементов. В ходе анализа текстов выявляются средне- и ранненововерхненемецкие особенности, черты, характерные для юго-восточных, восточнофранкского и нюрнбергского диалектов, а также орфографические особенности, представленные в исследуемых рукописях. Причины отличий графико-орфографических систем исследуемых текстов от фонетической системы ранненововерхненемецкого и межтекстовые различия подлежат интерпретации. Анализ особенностей скрипториев позволяет определить место графико-орфографических систем в контексте ранненововерхненемецкой языковой динамики, а также степень влияния на них различных диалектов. При рассмотрении графико-орфографических особенностей исследуемых текстов во внимание принимается специфика письменной фиксации ранненововерхненемецкого и учитывается, что городской письменный язык и городской диалект являются разными источниками влияния на формирование письменной традиции каждого из скрипториев. Данное исследование позволяет сделать вывод о степени самостоятельности графико-орфографических систем рукописей и об узуальности нормы письменного языка исследуемого периода.

Ключевые слова: графико-орфографические особенности; морфологические особенности; монастырский узус; письменный язык; нюрнбергский диалект; ранненововерхненемецкий язык

ИНФОРМАЦИЯ ОБ АВТОРАХ

Гаврюшева, Александра Евгеньевна

Email: alexandra-gavr@mail.ru

Старший преподаватель кафедры иностранных языков гуманитарных факультетов

Для цитирования: Гаврюшева А. Е. О специфических графико-орфографических и морфологических чертах узуса монастырских скрипториев Нюрнберга XV века // Социальные и гуманитарные знания. 2021. Том 7, № 1. С. 88-95.

(C) Гаврюшева А. Е., 2021

Статья открытого доступа под лицензией СС BY (https://creativecommons.org/licenses/by/4.0/) 


\section{Введение}

Письменный язык Нюрнберга XV века представляет интерес для исследователей в силу ряда причин. С одной стороны, он находится на стыке трех диалектных ареалов: восточнофранкского, севернобаварского и тюрингского, следствием чего становится междиалектная интерференция в письменных памятниках ранненововерхненемецкого периода. Такие тексты являются гетерогенными, нестабильными языковыми образованиями $[1$, c. 243]. С другой стороны, ориентация рукописей и первых печатных изданий, созданных в Нюрнберге, на читателей из других регионов [2, с. 15] способствует появлению наддиалектных черт в письменных памятниках еще до появления прескриптивной нормы.

Несмотря на то, что средневековые тексты привлекают внимание как зарубежных, так и отечественных лингвистов $[2 ; 3 ; 4 ; 5]$, духовная и богословская литература этого периода оказалась исследована в значительно меньшей мере, чем художественные тексты и грамоты. При этом переписчики и авторы средневековых духовных текстов по уровню образованности, степени влияния на других авторов, размеру целевой аудитории, количеству списков с их работ существенно отличаются от прочего городского населения. Кроме того, именно появление монастырских школ и университетов в немецкоязычном языковом пространстве способствует тому, что число текстов на немецком становится сравнимым с количеством изданий на латинском языке [6, с. 137].

Регулярное пополнение монастырских скрипториев рукописями и первыми печатными изданиями неизбежно приводит к формированию определенной письменной традиции скрипториев, однако в связи с отсутствием прескриптивной нормы каждый писец самостоятельно формирует графико-орфографическую систему, включая в нее надрегиональные тенденции, особенности местного и городского диалектов. Подобная вариативность осложняет анализ графико-орфографической системы, поскольку не во всех случаях возможно определение индивидуальных границ варьирования.

С одной стороны, рукописные традиции и узус конвента не могут не найти отражения в графико-орфографическом портрете писца. С другой стороны, учитывая дискуссионность выделения собственно нюрнбергских $[7 ; 8]$ и даже собственно восточнофранкских черт в ранненововерхненемецкий период [9; 10], вопрос о самостоятельности графико-орфографических систем каждой отдельной рукописи и сформированности письменной традиции каждого скриптория стоит особенно остро. В ходе настоящего исследования будут рассмотрены графико-орфографические и некоторые морфологические черты текстов, созданных в двух крупнейших скрипториях Нюрнберга XV в., что позволит сделать вывод о том, в какой степени набор графико-фонетических и морфологических особенностей каждого текста индивидуален либо подвержен воздействию письменной традиции скриптория.

В качестве материала исследования были выбраны тексты рукописей, созданных в XV в. в доминиканском конвенте святой Екатерины и конвенте святой Клары. Для удобства в тексте статьи рукописи обозначаются в соответствии с их местом хранения.

1. Staatsbibliothek Bamberg, Msc. Patr. 65, früher Q.V.6, далее обозначаемая $B a$.

2. Stadtbibliothek Nürnberg, Cod. Cent. VI, $43^{\mathrm{h}}$, далее обозначаемая Nu1, представляющая собой сборник из нескольких текстов, составленный двенадцатью различными переписчиками [11].

3. Staatsbibliothek zu Berlin - Preußischer Kulturbesitz, mgq 1421, далее обозначаемая $B e$. 
4. Cod. III 1. oct. 41, Augsburg Universitätsbibliothek, ein Gebetbuch für Klarissen, далее обозначаемая $A 1$.

5. Cod.I.3, Augsburg Universitätsbibliothek, далее обозначаемая A2.

6. Will II, 22.oct., Nürnberg, Stadtbibliothek, Heinrich v. St. Gallen: Passionstraktat, далее обозначаемая $\mathrm{Nu} 2$.

7. Nürnberg, Stadtbibliothek, Amb. 67 quart., далее обозначаемая Nu3. Данная рукопись принадлежит перу трех переписчиков [Там же].

Кроме того, в ряде случаев к исследованию привлекались другие тексты сборника $N u 1\left(4^{\mathrm{v}}-59^{\mathrm{v}}, 60^{\mathrm{v}}-61^{\mathrm{v}}, 64^{\mathrm{v}}-75^{\mathrm{v}}\right)$.

\section{Методы}

Задачам настоящего исследования отвечает использование всех текстов каждой из рукописей, благодаря чему становится возможна точная количественная оценка графико-орфографических и морфологических феноменов, представленных в каждом тексте, а также выявление особенностей их позиционного распределения. Кроме того, такой объем исследуемых текстов предоставляет возможность для подтверждения или опровержения существования статистически значимой корреляции графико-фонетических отношений в разных позициях и морфемах [12, с. 43].

Для выявления графико-орфографических особенностей каждого текста необходимо было получить точные количественные данные о различных графематических феноменах, их дистрибутивных особенностях, частотности их употребления, для чего на первом этапе исследования был использован статистический метод. В ходе исследования были использованы лингвистические редакторы за авторством А.В.Андреева (ИЛИ РАН) и Е. В. Гаврюшева (независимый разработчик).

Каждый исследуемый текст рассматривается как целостное образование, состоящее из взаимосвязанных элементов, для их анализа используется системный подход. Система, на основе которой осуществляется описание графико-орфографических отношений, была разработана Г.Коллером [2] и М.Эльменталером [13], а в качестве соответствующей классификационной схемы используется реконструированная В. Мозером [14] фонематическая система, свойственная ранненововерхненемецкому в юго-восточной части Германии. Использование сравнительно-исторического метода позволяет определить место графико-орфографических систем в контексте ранненововерхненемецкой языковой динамики, а также степень влияния на них различных диалектов.

Графические особенности каждого текста рассматриваются отдельно, а затем сопоставляются с графико-орфографическими системами других переписчиков. Их сопоставление между собой и с фонетической системой, характерной для ранненововерхненемецкого в юго-восточной части Германии, позволяет выявить, какие особенности можно считать чертами письменной традиции скриптория и городского диалекта исследуемой эпохи [12]. Причины отличий графико-орфографических систем исследуемых текстов от фонетической системы ранненововерхненемецкого и межтекстовые различия подлежат интерпретации. дующие:

Среди графико-орфографических явлений особенную релевантность имеют сле-

- сохранение оппозиции $b / p, d / t$ в разных позициях в слове;

- ослабление оппозиции сильного согласного, обозначаемого $f$ и $f f$ после кратких гласных, и слабого согласного, обозначаемого $f$ и $v$;

- устранение оппозиции $s \sim Z$. 
При рассмотрении графико-орфографических особенностей исследуемых текстов во внимание принимается специфика письменной фиксации ранненововерхненемецкого. Региональные варианты литературного языка, письменный узус этого периода не совпадают с особенностями систем местных говоров и диалектов. В письменном языке зачастую используется разный набор наддиалектных и региональных признаков, в некоторых случаях особенности, заимствованные из разных территориальных языковых вариантов, противоречат друг другу. Таким образом, городской письменный язык и городской диалект не тождественны и являются разными источниками влияния на формирование письменной традиции каждого из скрипториев.

\section{Результаты}

\section{Скрипторий конвента святой Екатерины}

B текстах из рукописей $\mathrm{Nu} 1, \mathrm{Nu}^{1}{ }^{1}$ и Ве из скриптория конвента святой Екатерины можно выделить общие черты. К ним относятся:

1. Средневерхненемецкие особенности.

- сохранение средневерхненемецкого $\hat{\imath}$, слабая представленность дифтонгизации;

- ослабление оппозиции $f \sim p$ между гласными;

- преобладание средневерхненемецкой парадигмы атематических и стяженных глаголов [15];

- использование средневерхненемецких форм инфинитива;

- употребление кратких личных форм в индикативе;

- использование непрефигированных причастий прошедшего времени;

- применение переходных личных форм глагола sein.

2. Ранненововерхненемецкие особенности.

- эпентеза $e$ в безударных аффиксах;

- сохранение оппозиции $<d>\sim<t>$ в начале слова.

3. Черты, характерные для юго-восточных диалектов.

- ослабление оппозиции <ei> <e> в ударном слоге;

- устранение оппозиции $<u>\sim<0>$ перед сонорными (что свойственно как восточнофранкским говорам, так и нюрнбергскому письменному языку, заимствовавшему эту особенность из местного диалекта);

- ослабление оппозиций $<p f>\sim<f>$ и $<f>\sim<p f>$ после сонорных или гласных;

- эпентеза $b, p$ между лабиальными и дентальными.

4. К числу графико-орфографических особенностей, характерных для средненемецких диалектов и представленных во всех рукописях, относятся оппозиция $<a>\sim$ $<0>$ и эпентеза $n$ перед глухими гуттуральными смычными на стыке морфем.

5. Нюрнбергское устранение оппозиции $\langle g>\sim<c h>$ на стыке морфем перед суффиксом-keit.

6. Орфографические особенности.

- распространенность написания $v$ для передачи $u$ и $f$;

- использование $j$ и у для передачи особого качества $i$ (в основном для обозначения краткости гласного).

Несмотря на то, что для всех исследуемых графико-орфографических систем характерны ранненововерхненемецкие колебания, каждая из них обладает определенной

\footnotetext{
${ }^{1}$ Тот факт, что рукописи Nu1 и Nu3 составлены несколькими писцами, облегчает выявление особенностей, общих для всех текстов и поэтому характеризующих письменную традицию скриптория в исследуемый период.
} 
самостоятельностью и собственным набором графико-орфографических и морфологических особенностей. Однако во всех рукописях наблюдаются общие тенденции и закономерности, неизменные в текстах, созданных разными писцами на протяжении всего $\mathrm{XV}$ в., позволяющие судить о сформированности стабильной письменной традиции скриптория.

Узус конвента святой Екатерины характеризуется относительной гомогенностью графико-орфографических систем, во всех рукописях, созданных в XV в., наблюдается стремление к использованию средневерхненемецких особенностей, следование современным им языковым тенденциям для них не характерно. Отражение ранненововерхненемецких особенностей осуществляется во всех рукописях по-разному и зависит от предпочтений переписчицы. В большинстве текстов писцы используют традиционные особенности графико-орфографической и морфологической систем.

В каждом исследуемом тексте, составленном в конвенте святой Екатерины, представлен свой набор элементов севернобаварских и восточнофранкских говоров, однако для письменного узуса конвента характерна слабая представленность особенностей нюрнбергского городского диалекта и повсеместное использование черт юго-восточных говоров, а также элементов средненемецкого территориального языкового варианта. Кроме того, для всех текстов, созданных в конвенте в XV в., характерно использование определенных орфографических особенностей, не свойственных письменному узусу Нюрнберга и потому специфичных для данного скриптория.

\section{Скрипторий конвента святой Клары}

Рукописи, созданные в конвенте святой Клары, отличаются большей гетерогенностью, разница между графико-орфографическими и морфологическими портретами каждой переписчицы более существенна, однако можно выделить общие особенности для всех текстов данного конвента:

1. Ранненововерхненемецкое использование геминат в конце морфемы и слова.

2. Южно-немецкие особенности (в основном свойственные севернобаварским диалектам).

- ослабление оппозиции $<e>\sim<\ddot{o}>$ и $<e>\sim<0>$ в начале слова перед буквосочетанием $p f$ (как в epffel öpffeln). Особенно широко данное явление представлено в $A$ и $N u 2$, средненемецкая лабиализация в этой позиции свойственна и рукописям из скриптория святой Екатерины, однако в меньшей степени. В нюрнбергском письменном языке она получает распространение во второй половине - конце XV в. [14, с. 108];

- редукция е в безударных суффиксах;

- использование $p$ в начале и середине слова перед гласным;

- употребление $b$ перед сонорными и после назальных;

- ослабление оппозиции $\langle b>\sim<w>$;

- использование $d t$ в конце слова после назальных;

- устранение оппозиции < $t>\sim<>$ в начале слова в превокальной позиции;

- эпентеза $е$ в безударной позиции;

- использование sch после назальных и сонорных;

- употребление формы инфинитива gesein, характерное для юго-западных диалектов.

3. Особенности нюрнбергского письменного узуса.

- ослабление оппозиций $<e u>\sim<i>,\langle u>\sim<0>,\langle e>\sim<u>$;

- применение средневерхненемецких форм претерита hetten, thetten;

- употребление глагола tun в форме претерита множественного числа с корневым $a$; 
4. В отдельных словоформах сохранение фонетических значений $s \sim z$ в интервокальной позиции (grose, geweszen, diesze, geleszen в Nu2).

5. Севернобаварские особенности.

- использование $p$ в начале слова и $b$ после сонорных;

- применение геминаты $g g$ для передачи $/ g /$ в середине и конце слова;

- преимущественное употребление $c k$ для обозначения $/ k /$;

- переход $t>d$ после назальных и сонорных;

- распространенность суффикса -nus;

- употребление полных форм steen, geen;

- использование смешанной формы seind/seindt;

6. Орфографические особенности.

- использование и для обозначения /u/;

- распространенное написание $f$ в начале слова для передачи $/ f /$;

- использование $i$ в начале слова в превокальной позиции при передаче $j$ на письме.

Таким образом, средневерхненемецкие особенности, черты восточнофранкских говоров, особенности нюрнбергского письменного языка или городского диалекта в текстах представлены неравномерно, и их набор колеблется в зависимости от предпочтений переписчицы. Письменный узус скриптория второй половины XV в. - начала XVI в. характеризуется преимущественным использованием ранненововерхненемецких особенностей, следованием современным для переписчиц тенденциям в отображении фонетических изменений на письме. Кроме того, во всех текстах, созданных в данном скриптории, повсеместно используются графико-орфографические особенности юго-восточного наддиалектного территориального варианта, севернобаварских говоров и некоторые элементы морфологической системы юго-западных диалектов, не характерные для узуса Нюрнберга и местного диалекта. Письменной традиции скриптория также свойственно употребление некоторых специфичных только для него орфографических особенностей.

\section{Обсуждение}

Таким образом, для письменной традиции скриптория конвента святой Екатерины характерно использование средневерхненемецких особенностей, слабая представленность черт нюрнбергского городского диалекта, употребление особенностей юго-восточных и средненемецких говоров. Для письменного узуса скриптория конвента святой Клары характерны ранненововерхненемецкие особенности, черты юго-западных диалектов, севернобаварских говоров и юго-восточного наддиалектного территориального варианта.

Элементы городского узуса и восточнофранкских говоров распространены в исследуемых рукописях в разной степени. Среди морфологических особенностей, свойственных нюрнбергскому письменному узусу и используемых в исследуемых рукописях, можно отметить применение средневерхненемецких форм претерита hetten, thetten и употребление глагола tun в форме претерита множественного числа с корневым $a$. В большей степени использование черт нюрнбергского письменного языка характерно для рукописей из скриптория конвента святой Клары. Во всех исследуемых текстах представлены особенности восточнофранкских и средненемецких говоров, большее их количество свойственно текстам из скриптория конвента святой Екатерины.

Графико-орфографическая и морфологическая система каждого писца демонстрирует определенную самостоятельность, обусловленную отсутствием общей обязательной письменной нормы в исследуемый период [16, с. 1]. Для каждого текста характерен 
индивидуальный набор морфологических и графико-орфографических элементов, однако тексты, созданные в одном скриптории, обладают общими чертами и закономерностями, характерными для письменной традиции данного конвента. Использование особенностей, характерных для узуса скриптория, подтверждает узуальность нормы исследуемого периода.

\section{Ссылки / References}

1. Anders C. A. Wahrnehmungsdialektologie: das Obersächsiche im Alltagsverständnis von Laien. Berlin-New York: De Gruyter, 2010.476 S.

2. Koller G. Der Schreibusus Albrechts Dürers. Graphematische Untersuchungen zum Nürnberger Frühneuhochdeutschen. Wiesbaden: Steiner, 1989. 256 S.

3. Klepsch A. Lautsystem und Lautwandel der Nürnberger Stadtmundart im 19. und 20. Jahrhundert. Tübingen: De Gruyter, 1988. 456 S.

4. Баева Г. А. HIC ET NUNC: К вопросу о текстообразующих маркерах устной рецепции в средневерхненемецкой литературе // Университетский научный журнал. СПб: СанктПетербургский университетский консорциум, 2017. № 31. С. 15-21.

5. Бондарко Н. А. Анонимная проповедь о воплощении Бога Слова в рукописи Cgm 176 из собрания Баварской государственной библиотеки // Индоевропейское языкознание и классическая филология - XIII (чтения памяти проф. И. М. Тронского). Материалы межд. конференции, проходившей 23-25 июня 2014 г. / Отв. редактор Н. Н. Казанский. СПб.: Наука, 2014. С. 52-60.

6. Гухман M. М., Семенюк Н. Н. История немецкого литературного языка IX-XV вв. М.: Наука, 1983. $200 \mathrm{c}$.

7. Van der Elst G. Aspekte zur Entstehung der neuhochdeutschen Schriftsprache. Erlangen: Palm \& Enke, 1987.169 S.

8. Müller P. O. Usus und Varianz in der spätmittelalterlichen und frühneuzeitlichen Schreibsprache Nürnbergs // Zeitschrift für germanistische Linguistik. Berlin-New York: De Gruyter, 2002. Bd. 30. S. 56-72.

9. Paul H. Mittelhochdeutsche Grammatik. 20. Aufl. von Hugo Moser und Ingeborg Schröbler. Tübingen: Max Niemeyer Verlag, 1969. 502 S.

10. Klepsch A. Fränkische Dialekte // Historsches Lexikon Bayerns. 2009. URL: http://www. historisches-lexikon-bayerns.de/Lexikon/Fränkische_Dialekte (дата обращения: 29.05.2018).

11. Schneider K., Zirnbauer H. Die Handschriften der Stadtbibliothek Nürnberg I: Die deutschen mittelalterlichen Handschriften. Wiesbaden: Harrassowitz Verlag, 1965. 594 S.

12. Glaser E. Graphische Studien zum Schreibsprachwandel vom 13. bis 16. Jahrhundert. Heidelberg: Winter, 1985.520 S.

13. Elmentaler M. Struktur und Wandel vormoderner Schreibsprachen. Berlin-New York: De Gruyter, 2003.164 S.

14. Moser V. Frühneuhochdeutsche Grammatik. Bd. I: Lautlehre. 1. Hälfte: Orthographie, Betonung, Stammsilbenvokale. Heidelberg : Winter, 1929. 215 S.

15. Гаврюшева А. E. Morphologische und graphisch-phonetische Varianz der athematischen und kontrahierten Verben in der Nürnberger Schreibsprache des 15. Jahrhunderts // Индоевропейское языкознание и классическая филология - XVIII. Материалы чтений, посвященных памяти профессора И. М. Тронского. СПб.: Наука, 2017. С. 154-174.

16. Straßner E. Graphemsystem und Wortkonstituenz. Schreibsprachliche Entwicklungstendenzen vom Frühneuhochdeutschen zum Neuhochdeutschen, untersucht an Nürnberger Chroniktexten. Mit 4 Mirkofiches. Tübingen: De Gruyter, 1977.171S. 